Water Resources Development,

Vol. 21, No. 4, 663-675, December 2005

Routledge

Taylor \& Francis Grou

\title{
Rainfall Insurance: A Promising Tool for Drought Management
}

\author{
KIMBERLY A. ZEULI* \& JERRY R. SKEES $\dagger$ \\ *Department of Agricultural and Applied Economics, University of Wisconsin-Madison, Madison, WI, USA; \\ ${ }^{\dagger}$ Department of Agricultural Economics, University of Kentucky, Lexington, KY, USA
}

ABSTRACT Diverse and complex water management systems have been created in many areas of the world to manage the risk of drought. The primary challenge is the inherent uncertainty of water supply and demand over time, which makes the process of correctly allocating water rights annually a difficult and costly task. As a result, risk averse water authorities make overly conservative estimates of water supply. This paper introduces the use of a rainfall index contract as a tool to improve drought management. An irrigation district in New South Wales, Australia, is used as an illustration of the concept.

\section{Introduction}

In areas of the world where water is in short supply or where demand for water is constantly threatening to outstrip supply, diverse and complex water systems have been created to manage the risk of drought. In quasi-governmental water markets, a common institutional arrangement, a local water authority typically allocates water rights annually among competing water users based on estimates of current water reserves, future inflows, and future demand. The challenge is that water supply and demand are both highly variable across time, making accurate predictions almost impossible, not to mention extremely costly. As succinctly stated by Howitt et al. (1979, p. 1), "A 'normal' water year hardly exists except as a statistical average. Actually, most years are dryer than normal with the average being raised by a few extremely wet years". This process is made more difficult in the presence of drought conditions, especially since long droughts are often frequent events (Dudley, 1988).

Water supplies are inherently uncertain since they are a function of largely unpredictable weather patterns and events. Water reserves in basins and dams are depleted during dry seasons (times of high water use) and subsequently replenished during the rainy season, with important additions from snow run-off in some areas. Although the consequence of this cycle for water reserve levels can in some regions be fairly predictable over the course of a year (although this is often not the case), El Niño events remind the world that weather patterns and, thus, water levels are never completely predictable.

Correspondence Address: Kimberly A. Zeuli, Department of Agricultural and Applied Economics, University of Wisconsin-Madison, 329 Taylor Hall, 427 Lorch Street, Madison, WI 53706-1503, USA. zeuli@aae.wisc.edu

0790-0627 Print/1360-0648 Online/05/040663-13 C 2005 Taylor \& Francis

DOI: $10.1080 / 07900620500258414$ 
The presence of asymmetric information makes water demand estimation equally problematic. Some water users may have saved or 'banked' their previous year's water allocations or, in the case of farmers, increased their irrigation efficiency (thus requiring less water) without reporting these changes to the water authority. Water users may also have on-farm storage systems (that allow them to save any excess water) and conjunctive water systems, groundwater, and other unregulated water sources.

As a result of water supply and demand uncertainty, water authorities typically make extremely conservative annual water supply and allocation estimates. As a result, in some years they may have excess water supplies in reserve at the end of the year. Although conservative estimation certainly helps mitigate some of the risk associated with drought conditions, it is very inefficient. Stored water (whether on the farm or in a reservoir) is an imperfect insurance medium since it often leads to wasted water (Dudley, 1988). It steadily evaporates and can also lead to reservoir spills in times of excess rainfall (and/or low demand). Further, it can be assumed that water users can better optimize their temporal allocations of water since they hold more information than the water authority. The water authority may allocate more or less in a given year than will be used. The water users may also have different risk preferences than the water authority. For example, if the water authority is more risk averse than even some of the water users, it will allocate less water than will be used. If the water authority is less risk averse, water users may attempt to self-insure against drought by hoarding water rights or storing their own water.

Water markets that allow temporal trading of water allocations address some of this inefficiency. However, water markets are still inherently uncertain and the presence of uncertainty impedes the efficient functioning of any market (Arrow, 1964). The purpose of this paper is to describe how a rainfall index contract (RIC) (a relatively new insurance product) works and how it can be used to increase the efficiency of drought management in a water market context. Although several papers describe weather-based derivatives (and their potential applications in agriculture) from a theoretical perspective (e.g. Martin et al., 2001; Turvey, 2001), their technicality precludes a broad readership, especially those unfamiliar with insurance literature. In addition, none has yet applied the concept to a water market. The subsequent section describes RICs in more detail for a more general audience. An established water market in New South Wales (NSW), Australia, is used to illustrate the implications of incorporating RICs into a water market. Using time series rainfall data, numerical simulations examine the impact on a hypothetical irrigator. This is followed by a more general discussion of the efficiency gains at the water market level and the implications for water demand. NSW serves as an appropriate example since it encompasses the largest irrigation industry in Australia and struggles with chronic water shortages (Crase, 1999). The paper concludes with a discussion of the challenges associated with implementing RICs and identifies future research issues.

\section{Insurance Alternatives for Managing Water Supply Risk}

All insurance products involve different types of contingent claims contracts, where a payment (indemnity) is contingent upon certain conditions or events. Insurance contracts (as opposed to futures contracts) are generally the optimal choice when the risks being insured are independent (e.g. automobile accidents). With independent risk, only a few 
contract holders are likely to suffer a loss at any one time. When risk is systemic, i.e. the risk of a particular event is highly correlated across individual agents, using insurance to manage risk is costly (Jaffee \& Russell, 1997). For example, farmers in the same region can face correlated crop loss given adverse weather conditions such as drought conditions or excessive rain. Therefore, the likelihood that an insurance provider will have to pay a large number of claims increases as more contract holders are added to an insurance pool. As a result, private insurance companies have been unwilling to insure systemic risk.

New innovations in insurance markets are changing that norm. Private insurance and financial companies are beginning to offer several different types of contingent claim instruments, including weather-based index contracts, to cover systemic risk exposure and as portfolio diversification strategies (Skees \& Barnett, 1999; Skees, 2000). The idea of basing indemnity payments on weather, such as rainfall or temperature, is not new (e.g. Sanderson, 1943). The difficulties of providing rainfall insurance in Australia spurred a debate in the 1980s (Bardsley et al., 1984; Quiggen, 1986; Patrick, 1988). As Mahul (2001) points out, the primary challenge to early weather insurance tools arose from indemnity pay-offs being tied to yield effects rather than strictly to the event itself (the cause of the risk).

Insuring an outcome that is a function (even partially) of human influence gives rise to serious adverse selection and moral hazard problems. Controlling these problems (monitoring) can be costly, leading to higher insurance premiums (Miranda, 1991; Skees and Barnett, 1999; Skees, 2000). For example, water markets could introduce insurance contracts based on reservoir water levels. However, if management of the reservoir influences water levels, the water authority could manipulate the water system in a selfserving manner or manage it in such a way that would increase water supply risk (a moral hazard problem). ${ }^{1}$ In addition, the contract might be purchased by water authorities facing the greatest water supply risk (adverse selection) and instead of improving their management or the system they would simply buy insurance. In contrast, contracts based on weather events decrease information asymmetries as well as the influence of contract agents, therefore diminishing adverse selection and moral hazard problems (making the insurance more cost-effective and increasing the likelihood that a private insurance provider would write such contracts). RICs, for instance, are based on aggregate rainfall levels (from as many years as possible) measured by reliable weather stations located in the relevant watershed. This information would be available to both the insurer and the contract holder. Further, the pay-offs under the current class of weather-based index instruments are triggered by specific and objective weather outcomes. For example, with an RIC, an indemnity payment is made to the contract holder whenever the actual rainfall measure falls below a certain percentage of the average rainfall.

RICs may not be appropriate for all water markets. Historic rainfall levels need to be highly (and positively) correlated with historic reservoir water levels. In some water systems, water levels may be more a function of temperature, snowmelt, or other water sources. In these instances, more comprehensive weather-based indexes (e.g. incorporating snow levels, temperature, etc.) would be more appropriate. If water levels are strictly a function of weather events and not management (i.e. weather events and water levels are perfectly correlated), water supply risk can also be managed with a straightforward water level contract. 


\section{Water Market Inefficiency: The Murrumbidgee Irrigation Area}

The water allocation system in the Murrumbidgee Irrigation Area (MIA), an irrigation district in NSW (see Figure 1), nicely illustrates the general inefficiencies caused by water supply uncertainty and the potential for RICs. A mixed system of markets and government administration allocates water resources in the MIA (Topp \& McClintock, 1998; Danzi, 1999). Since the following is a general description of the system as it was operating in 2005 , it may not be a completely accurate representation of the system that currently exists for all irrigators in the MIA. Regardless, the exact details of the system are not crucial for the purpose of this paper, which is to illustrate the incorporation of insurance into a fairly common type of water market. ${ }^{2}$

Water entitlements are required to use water from all regulated and unregulated rivers as well as for groundwater extractions. The individual irrigator decides how many water entitlements to purchase. Although the entitlements give them the right to use a certain quantity of water, they may not receive their full entitlement. The local water authority (Murrumbidgee Irrigation) determines the annual allocations - how much they will actually receive per entitlement. There are two types of entitlements-high security and general security (Topp \& McClintock, 1998). Holders of high security entitlements are guaranteed to receive their full entitlement except during severe droughts. Holders of general security entitlements, which constitute the bulk of the entitlements in NSW (Crase, 1999), have no guarantees, and usually face attenuated rights (i.e. a proportion of their entitlement). For example, an irrigator may have purchased entitlements to $100 \mathrm{Ml}$ of water. If they are high security entitlements he or she may receive all $100 \mathrm{Ml}$; if they are general security he or she may receive only 5-10 Ml. Research shows that high security water allocations remain unchanged in 97 out of 100 simulated years (Danzi, 1999). In contrast, holders of general security entitlements may never receive their full entitlement (Musgrave, 1997). ${ }^{3}$

At the beginning of each irrigation season (July), the local water authority announces the quantity of water that will be initially allocated to entitlement (water right) holders (Musgrave, 1997; Topp \& McClintock, 1998). ${ }^{4}$ The annual water allocation decision is based on current water reserve levels and conservative estimates of future water demand

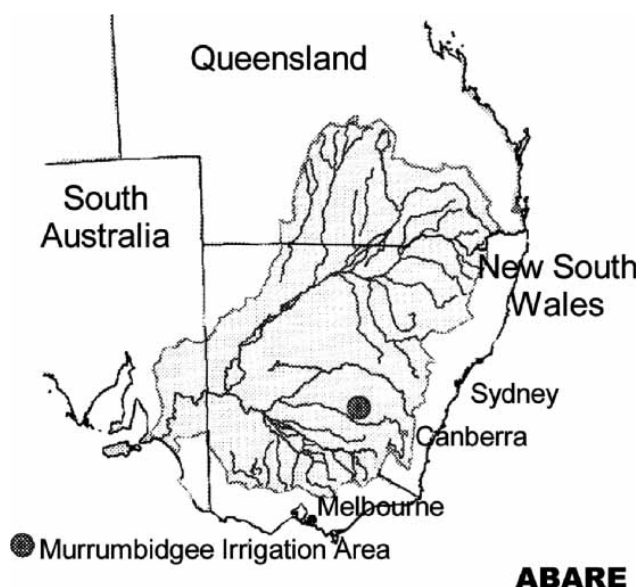

Figure 1. The MIA in NSW, Australia. 
and supply (Beare et al., 1998). Water demand, which varies by season and across years, is difficult to predict. Demand estimation is made more challenging by the fact that most farms in NSW have on-farm water storage systems, thus allowing them to store water for future use (Dudley \& Scott, 1993). They may also use conjunctive water sources or banked water allocations from previous years (Beare et al., 1998). The local water authority can (and typically does) adjust water allocations throughout the irrigation year to account for actual inflows and demand (Crase, 1999).

Estimating water supply is equally challenging, since water supply in NSW is "inherently unreliable" (Crase, 1999, p.20). In the MIA, the majority of the reserved water is contained in two water reservoirs, the Burrinjuck and Blowering dams (Beare et al., 1998). The Burrinjuck Dam has highly variable inflows in winter and early spring while the Blowering Dam is managed with regulated flows from a hydroelectric dam upstream. The dams generally start to be replenished in May and by early December the cumulated inflows into the reservoirs will largely determine the water supply available for irrigation during the summer growing season (planting occurs in October-November with harvest in February). To illustrate water supply volatility, the average monthly water level index (representing an average seasonal cycle based on water level data from 1968 to 1998) is compared to the actual monthly water level index for Blowering Dam in Figure 2. Several years clearly exhibit significant shortfalls: 1968, 1982, and 1997. Water levels also fell well below normal in 1979, 1980, 1987, and 1994.

Irrigators may purchase water entitlements from the water authority, or may trade water rights with other users, at any time during the irrigation (or 'water') year (July-June typically)..$^{5}$ Thus, they make an initial ex ante decision about how many entitlements to purchase (or retain) at the beginning of the irrigation year, after the annual allocations are announced but well in advance of the summer planting season (October-November). ${ }^{6}$

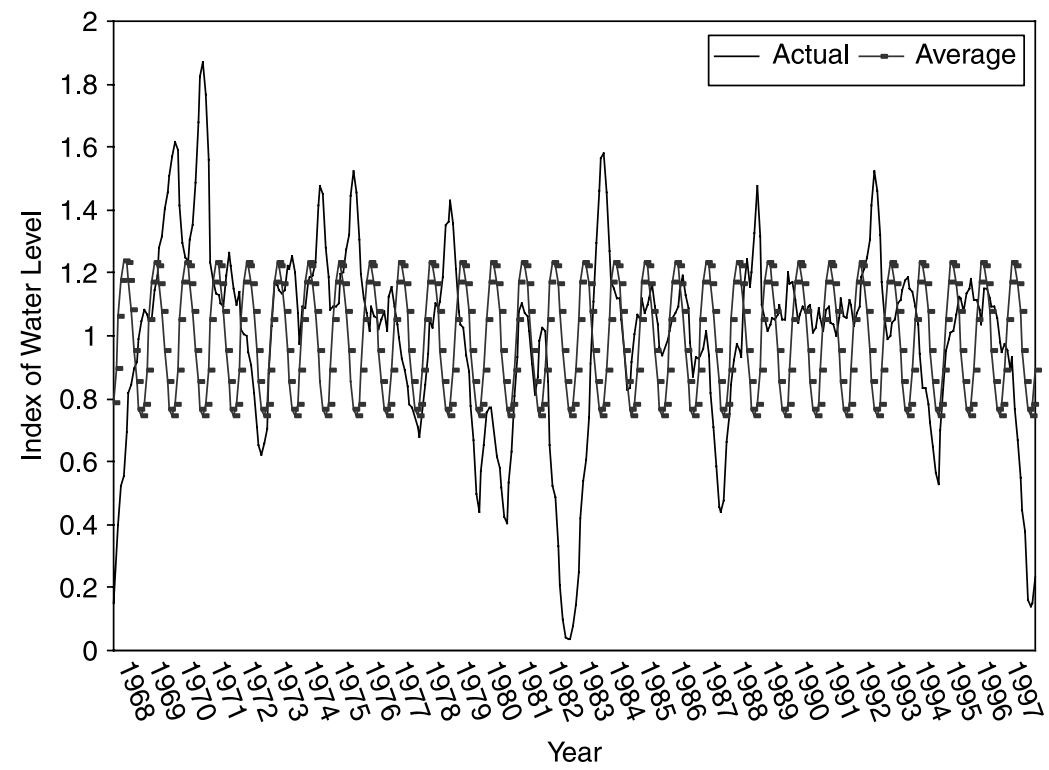

Figure 2. Actual and average monthly water level indexes for Blowering Dam, 1968-98. 
When making this decision, and the related decision about how many acres to plant, the irrigator faces four sources of uncertainty. First, it is difficult to predict water demand for an entire season given the inherent uncertainty of weather and crop health. Second, even if the irrigator was able to make a perfect prediction, the water authority can change its annual allocations throughout the season, providing more or less water than anticipated. Third, the price of water rights changes throughout the season, rising as demand outstrips supply and vice versa. Fourth, the crop price is also uncertain (unless the irrigator is able to lock in a contract price).

Water entitlement and planting decisions based on incorrect expectations can be costly. For example, the underestimation of water requirements or the overestimation of intraseason reallocations could leave farmers with either severe yield loss or increased production costs since water prices would most likely rise. In an optimal situation, high water prices would be offset by high commodity prices (due to a commodity supply shortfall). ${ }^{7}$ However, this would require at least some (high value) irrigators being able to purchase adequate water supplies to save their crops from others (low value users). In response, risk averse irrigators often self-insure (purchase more entitlements than they expect to use) to mitigate these risks. A 1996-97 survey of irrigators in NSW indicated that many hold excess entitlements as part of a hedging strategy (Beare et al., 1998). In addition to decreasing the efficiency of the water market, hoarding water rights is also potentially costly for the irrigator. Although they can trade their entitlements, in seasons with sufficient rainfall or high allocations (i.e. when they are not needed) there would probably be low demand and low prices. Further, potential bumper crops could drive down crop prices and the irrigators' revenues might not ultimately cover their production costs (which include the water rights). The following section looks at the potential impact an RIC could have on managing the risks associated with estimating water demand and supply.

\section{Constructing an RIC for the MIA}

If water supply in the MIA was strictly a function of weather events, the most straightforward insurance contract for MIA irrigators would be tied to reservoir water levels. Since management of the water system (via the dams) does, however, influence the water supply, this type of insurance instrument is not appropriate (for the reasons elucidated in the second section, i.e. insuring management decisions is not efficient). If rainfall and water levels in the two dams are correlated, a better alternative would be an insurance contract based on rainfall data. To estimate this correlation for the MIA, the authors obtained monthly rainfall data over 110 years (1889-1998) from three rainfall stations in the reservoirs' watershed as well as monthly water levels for Blowering and Burrinjuck dams over 31 and 13 years, respectively.

Because the monthly water levels in the two dams were $88 \%$ correlated (a Pearson correlation coefficient) during the 13 year period their data sets overlapped, and the time series data for Blowering Dam were lengthier, only Blowering Dam data were used for the regression estimation. Using 31 years (1968-98) of matching data, a simple linear regression with annual Blowering Dam December water levels as the dependent variable and the annual cumulative July-November rainfall as the explanatory variable was estimated. ${ }^{8}$ The model had an $R^{2}$ of $70 \%$, meaning rainfall during July-November explains over $70 \%$ of the variation in Blowering Dam water levels for the month of December. This finding suggests that it would be reasonable to use an RIC to manage the 
weather-related water supply risk in the MIA. With comprehensive time series data on all weather events that impact water levels in the two dams (e.g. snowfall, temperature, etc.), a more accurate weather-based index could be created. The authors were unable to obtain the data required to test these ideas.

The following section illustrates how an RIC would be constructed. The contract would be based on average cumulative rainfall levels for July-November. For each month $i(i=$ July, August, ..., November $)$ in each year $t(t=1,2, \ldots, T ; T=31)$, the rainfall levels reported from the three weather stations are averaged and this is used as the actual rainfall level for that month and year $\left(R_{t}^{i}\right)$. The cumulative rainfall for July-November for each year $t$ requires summing the actual monthly rainfall levels $\left(R_{t}^{c}=\sum R_{t}^{i}\right)$. The observed frequencies of cumulative rainfall during these 5 months (represented by the bars) as well as a rainfall probability distribution estimated from these observations (assuming a gamma distribution) are shown in Figure 3.

A trigger rainfall level (TR) (the rainfall level that 'triggers' an insurance payment) for any time period $t$ is based on the average cumulative rainfall (over 31 years) and the insurance coverage level $(C)$ purchased by the contract holder for that year:

$$
T R_{t}=\left(\sum_{t} R_{t}^{c} / T\right) * C
$$

The coverage level is a percentage chosen by the contract holder (an alternative way to think about the coverage level is that $C=1$-the deductible). For example, a $70 \%$ coverage level indemnifies the contract holder in all years when actual rainfall levels fall below $70 \%$ of the average rainfall. In years when rainfall is less then the average, but greater than $70 \%$ of the average, the contract holder would not receive any indemnity. Clearly, lower coverage levels would only insure the holder against infrequent (low probability) events. To illustrate this point, assume an average rainfall of $100 \mathrm{~cm}$. In most regions it is more likely that the insured would experience rainfall levels that were less than $70 \%$ of the average (less than $70 \mathrm{~cm}$ ) than rainfall levels that were less than $20 \%$ of the average

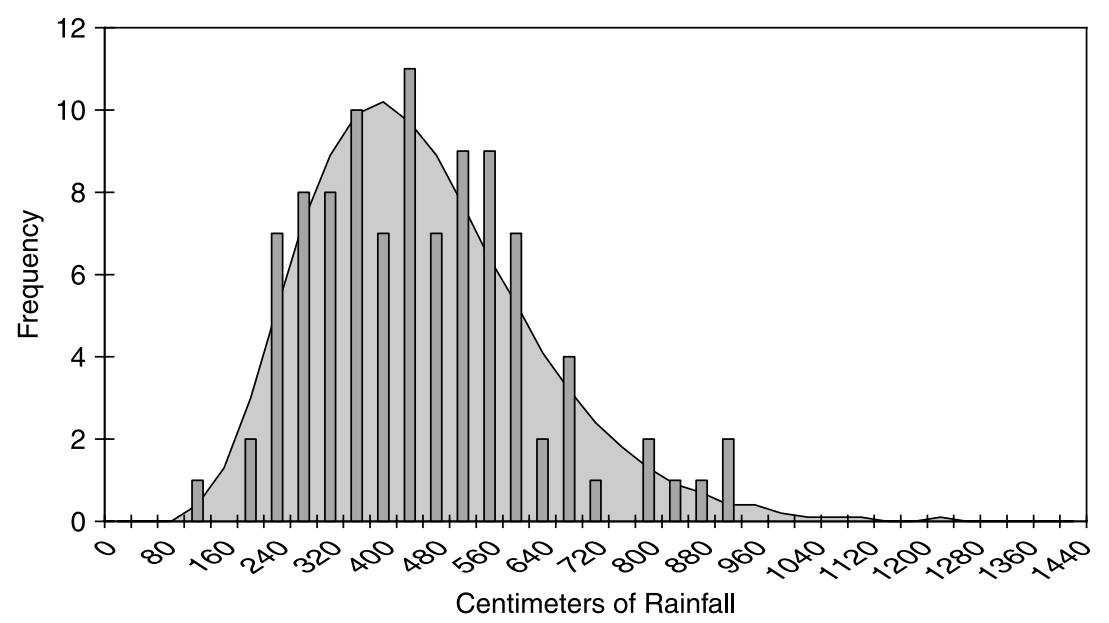

Figure 3. Probability distribution of cumulative rainfall during July-November 1968-98. 
(less than $20 \mathrm{~cm}$ ). In other words, in most regions drought conditions are less frequent than below normal rainfall levels.

The amount of money actually paid to the contract holder, the indemnity payment $\left(P_{t}\right)$, is a function of the differential between the actual cumulative rainfall and trigger rainfall levels as well as the level of protection purchased by the contract holder for that period $\left(D_{t}\right)$ :

$$
P_{t}=\left[\left(T R_{t}-R_{t}^{c}\right) / T R_{t}\right]^{*} D_{t}
$$

The level of protection, or liability, is the value the contract holder chooses to compensate himself for the anticipated loss (e.g. the value of a car if it cannot be salvaged or, in this case, the value of lost yield when a crop cannot be irrigated). For ease of calculation, assume the contract holder chooses a $\$ 1$ million liability. If the trigger rainfall level was $100 \mathrm{~cm}$ and the actual cumulative rainfall was $50 \mathrm{~cm}$, then the payment to the contract holder is $\$ 500000$.

Since an RIC is a contingent claim contract that serves as a risk-hedging mechanism, optimal hedging rules apply when choosing a liability level $(D)$. Therefore, it may be optimal for the irrigator to purchase more liability than the current value of the assets at risk. For instance, as discussed above, when there is a water shortage, water prices tend to increase. If a farmer purchased a rainfall contract to hedge against both drought conditions (lower crop yields and revenue) and higher water prices (i.e. water supply risk and water price risk), he or she would take the number of units of water they normally need and multiply that by some higher than average water price to determine how much of their income is at risk and thus how much liability to purchase. However, as this RIC is specified, the indemnity payment is also affected by the chosen coverage level $(C)$. A higher coverage level also increases the payment since it leads to a higher trigger level, which in turn means a higher percentage of the liability is paid. Higher coverage levels also increase the probability that the contract holder will receive an indemnity payment. The choice of coverage and liability levels also affects the price (premium) of the RIC. As with any insurance product, the premium is a function of the frequency and severity of the event. Thus, higher coverage levels or higher liability levels both increase indemnity payments and hence contract price.

\section{RIC Implications for Irrigators and Water Authorities}

There are several possible ways to introduce RICs into a water market. In the most straightforward approach, the water authority could simply sell rainfall contracts to water right holders any time prior to the indemnified rainfall season (July-November). Thus, the irrigator would know the current reservoir level but would be uncertain about rainfall levels during the key months that predict water supply for the summer growing/irrigation season (October-February). They would also be uncertain about the indemnity payments, which they would receive at the end of the planting season when actual rainfall measures were collected. The farmers who purchase an RIC would be insured against attenuated water allocations (i.e. insufficient irrigation or costly water) during the summer growing season.

The indemnity payments that would have been made to a hypothetical contract holder in the MIA, under various coverage levels, during 1968-98, are reported in Table 1. Liability was assumed constant at $\$ 1$ million. The actuarially fair premiums for $100 \%, 90 \%, 80 \%$, 
$70 \%$, and 60\% coverage levels are, respectively, $\$ 92600, \$ 67700, \$ 47400, \$ 34800$, and $\$ 24500 .^{9}$ The cumulative rainfall index involves dividing the cumulative rainfall for each year $t$ by the average annual cumulative rainfall for all years (1968-98), as specified in the following equation:

$$
I_{t}=R_{t}^{c} /\left(\sum_{t} R_{t}^{c} / T\right) .
$$

Thus, the index number provides the percentage of the average annual cumulative rainfall received in any year $t$. For example, $I=0.21$ in 1982 means that only $21 \%$ of normal (average) rainfall was accumulated during July-November. Since the average cumulative rainfall was $438 \mathrm{~cm}$, this means only $91.98 \mathrm{~cm}$ of rainfall actually fell in 1982 .

At the highest coverage level (100\%), indemnity payments were triggered in 10 of the 31 years; these are the same 10 years of Blowering Dam water level shortfalls apparent in Figure 2. The contract holder would have received the highest payment in 1982. Substantial indemnity payments would also have been made in 1997 and 1980, across all coverage levels. At the lowest coverage level (60\%), the contract holder would only have received payments in 3 of the 10 years. As with any insurance instrument, the potential exists for the RIC holder to experience a loss but fail to receive an indemnity payment. By purchasing RICs, however, irrigators would offset the portion of their income risk dependent on adequate water supply. They would be assured of either a sufficient water supply to generate normal crop yields or monetary reimbursement during droughts. This increased income security should create the incentive for irrigators to trade rather than amass excessive water rights since the RIC replaces their need to self-insure.

Theoretically, since the water authority could provide cash pay-offs (indemnities) in lieu of water, it should make less conservative estimates and instead base water right allocations on the most accurate estimates of water supply and demand. Furthermore, since it would be financially obligated to either deliver water or indemnity payments,

Table 1. Indemnity payments $(\$ 100000)$ for a rainfall index contract at various coverage levels ${ }^{\mathrm{a}}$

\begin{tabular}{lcccccc}
\hline & & \multicolumn{5}{c}{ Coverage level } \\
\cline { 3 - 7 } Cumulative rainfall index & Year & $100 \%$ & $90 \%$ & $80 \%$ & $70 \%$ & $60 \%$ \\
\hline 0.21 & 1982 & 7.9 & 7.7 & 7.4 & 7.0 & 6.5 \\
0.55 & 1997 & 4.5 & 3.9 & 3.1 & 2.1 & 0.8 \\
0.58 & 1980 & 4.2 & 3.6 & 2.8 & 1.7 & 0.3 \\
0.71 & 1987 & 2.9 & 2.1 & 1.1 & 0 & 0 \\
0.78 & 1994 & 2.2 & 1.3 & 0.3 & 0 & 0 \\
0.82 & 1972 & 1.8 & 0.9 & 0 & 0 & 0 \\
0.84 & 1977 & 1.6 & 0.7 & 0 & 0 & 0 \\
0.84 & 1968 & 1.6 & 0.7 & 0 & 0 & 0 \\
0.89 & 1979 & 1.1 & 0.1 & 0 & 0 & 0 \\
0.91 & 1983 & 0.9 & 0 & 0 & 0 & 0 \\
\hline
\end{tabular}

${ }^{\mathrm{a}}$ Assumes $\$ 1$ million in liability.

Source: Australian Bureau of Agriculture and Resource Economics. 
the incentives for the water authority to manage the system properly should be significantly improved.

\section{RIC Effects on Water Use}

RICs may help reduce total water demand from irrigators by diminishing the hoarding of water rights and on-farm storage of excess water. However, farmers have other strategies that reduce their exposure to water supply risk. The two most significant include investing in more water efficient irrigation technology and changing their crop mix or production methods to those that demand less water. Mahul (2001) finds that under certain conditions risk averse farmers respond to the introduction of weather insurance contracts by increasing their risk exposure. In the case of irrigation, which is a risk-reducing input, his findings imply that some farmers might increase their water supply risk exposure by decreasing their irrigation use, planting more irrigation acres, switching to higher value, higher water use crops, etc. In their more generalized research into the effect insurance has on input use, Chambers \& Quiggin (2001) establish a more complicated relationship. They find that providing insurance to farmers causes at least two responses. The pure-risk response agrees with Mahul's (2001) conclusion, i.e. farmers increase their risk exposure. But Chambers \& Quiggin (2001) also acknowledge that insurance influences the scale of the farm operation. The scale response can either increase or decrease the level of purerisk adjustment, depending on how the scale adjustment affects the farmer's risk profile. Thus, with the introduction of RICs, farmers may also increase their operations (planting more acres) and demand more water for irrigation.

Recent research by Carey \& Zilberman (2002) finds that the adoption of irrigation technology in the presence of a water market primarily depends on the market price of water. The introduction of RICs would effectively increase the price of water since the irrigator would pay the water market price as well as the insurance premium (either directly or indirectly as part of the price of water). Farmers who sell (buy) their water rights at higher prices have the incentive to invest in water-saving technology. Clearly, the relative price of the insurance is critical to the irrigator's on-farm decisions. If the RIC premium is quite low, farmers may find it less profitable to invest in additional watersaving technology. Therefore, subsidizing RICs may have undesirable effects: less efficient water use on farms and ultimately more demand for water. To avoid this problem, it may be possible to design a more complicated contract with a premium rate that is a function of a farmer's investment in technology that reduces water supply risk (e.g. different crop mixes or improved irrigation technology). However, such a contract would be subject to the same moral hazard problems discussed earlier if monitoring and sound underwriting did not accompany the contract.

The impact of RICs on a farm's conjuctive water system is also unclear. The substitution effect on groundwater use will also depend on the relative price of surface water (which again would reflect the insurance premium). In some instances, the assurance of revenue from the RIC may limit the irrigator's use of groundwater especially if the indemnity payments exceed expected crop revenues minus some accounting for the longterm costs or risks associated with using groundwater (e.g. higher salinity; see Economist (2000)). In other words, with indemnity payments farm income may still increase in times of drought (or at least not decrease) without utilizing any groundwater. In the absence of accounting for groundwater costs, or if the expected net profits are high, farmers may 
substitute groundwater, produce their crops, and also collect their indemnity payments. More applied water market research is clearly warranted before making any solid conclusion regarding the impact of RICs on water demand.

\section{Implementation}

The implementation and efficacy of an RIC depend on sufficient, reliable (tamper-proof) data, accurate pricing, and affordability (Skees, 2000; Martin et al., 2001). While data manipulation may be a concern, individual rainfall station measurements can always be corroborated by comparing them with adjacent stations or with remote-sensing data. Finding lengthy time series data for rainfall and water levels may be a more significant challenge since they are necessary for accurately pricing the contract. Since the RIC premium is a function of the probability of the event, it depends on the number and timing of the years over which the probability is assessed. While lengthy time series of rainfall data certainly exist, more than 50 years of data will still not guarantee an accurate probability assessment. For example, the El Niño Southern Oscillation (ENSO) phenomenon could change the probability of the insured events (Podbury et al., 1998). Therefore, it may be necessary to adjust the cost of the insurance when an ENSO event is confirmed, although this would require sufficient lead-time between knowledge of the pending event and the time of selling insurance. Selling multi-year contracts (that cover individual years 3-5 years into the future) prior to ENSO signals may be the better alternative. Multi-year contracts are often used by the reinsurance industry.

In some regions of the world where drought conditions occur frequently, RICs could be prohibitively expensive at higher coverage levels. In these areas, the RIC may only be used to cover infrequent, extreme weather events or low levels of liability (and thus be more affordable). With RICs, like other insurance products, the potential contract holders would choose coverage and liability levels that they could afford. Although they might not be able to afford optimal insurance coverage, if the contract holders are risk averse the RIC would still improve their welfare.

The use of RICs may have the greatest impact in developing countries, where droughts can virtually wipe out a farmer's total farm income as well as their subsistence food. As discussed above, however, the impact of RICs on crop production patterns is not clear. In the case of developing countries, this issue is especially important since RICs could cause a move away from diversified agriculture towards more monocultures. The unique political economies of developing countries pose unique challenges, the full discussion of which is beyond the scope of this paper.

\section{Conclusion}

Complex and diverse water systems have been created in many parts of the world to improve water allocation in general and more specifically to manage drought. The difficulties in accurately predicting water supply and demand (both of which vary over time) create inefficiencies in these systems. When temporal trading in water rights is allowed, the risk of drought still decreases the volume of trade since agents are more likely to hoard water rights as a hedging strategy, rather than trade at the margin. This paper presents a partial solution: the incorporation of RICs. Since the water authority could provide cash pay-offs (indemnities) in lieu of water, it should make less conservative 
estimates and, instead, base water right allocations on the most accurate estimates of water supply and demand. RICs would assure irrigators of either sufficient water supply to generate normal crop yields or monetary reimbursement during droughts. This increased income security should create the incentive for farmers to trade rather than hoard their water rights since the RIC replaces their need to self-insure. However, it should be recognized that the RIC would not be able to reduce the risk of attenuated water rights due to government intervention. In the presence of such risk, the full impact of the RIC would not be realized (i.e. some irrigators would still hold more water rights than necessary as self-insurance against that risk).

It is also important to recognize that at this point it is unclear as to the full effect the introduction of RICs may have on water demand. Irrigators may take on more water supply risk, planting more acres, switching to more high value, high water use crops, etc. The result of this behaviour would be to consume more water, not less, a significant problem for regions such as NSW where water shortages are already severe. More research is clearly needed to accurately assess the impact RICs might have on farm-level water use decisions. It is hoped that future research will incorporate the RIC concept into stochastic models that analyse the management of water supply and demand in uncertain environments. Further research also needs to fully assess the costs and benefits of incorporating RICs into water markets relative to other drought risk management options. In some countries, RICs may not be a feasible alternative. Although the unique conditions of the water management system being considered will ultimately determine the net result insurance will have on drought management, this paper suggests some intriguing possibilities. In the end, few areas of the world can afford to ignore the possibilities of a new approach to drought management.

\section{Notes}

1. For example, the water authority would have an incentive to cause a water shortfall if it was the insured (the contract holder) and the potential indemnity payment exceeded expected water market revenues.

2. For a more complete description of the water market situation in NSW see Crase (1999).

3. Murrumbidgee Irrigation, the company that operates the water market in the MIA, posts the allocations on its website (http://www.mirrigation.com.au).

4. The irrigation or 'water' year is typically 1 July-30 June, but drought conditions may cause an earlier deadline (e.g. May).

5. Irrigators who wish to sell their water rights post the quantity of water and price on the water market website (http://www.murrumbidgeewater.com.au).

6. Water users purchase an entitlement and are also charged a fixed price per unit of water based on their entitlement (high security users are charged a higher fee) and water usage (http://www.mirrigation.com.au).

7. During the California drought of 1976-77, net farm income actually increased because the prices of California's specialty crops rose (Howitt \& M'Marete, 1989).

8. Different sets of continuous months were tested.

9. The actuarially fair premium $=$ the actuarially fair premium rate $\times$ the liability. The actuarially fair premium rate $=$ the expected indemnity/the liability.

\section{References}

Arrow, K. J. (1964) The role of securities in the optimal allocation of risk bearing, Review of Economic Studies, 31, pp. 91-96.

Bardsley, P., Abey, A. \& Davenport, A. (1984) The economics of insuring crops against drought, Australian Journal of Agricultural Economics, 28, pp. 1-14. 
Beare, S. C., Bell, R. \& Fisher, B. S. (1998) Determining the value of water: the role of risk, infrastructure constraints, and ownership, American Journal of Agricultural Economics, 80, pp. 916-940.

Carey, J. M. \& Zilberman, D. (2002) A model of investment under uncertainty: modern irrigation technology and emerging markets in water, American Journal of Agricultural Economics, 84, pp. 171-183.

Chambers, R. G. \& Quiggin, J. (2001) Production insurance and input use: an analytical framework, Working Paper 99-03, Department of Agricultural and Resource Economics, University of Maryland.

Crase, L. (1999) Water markets as a vehicle for water reform: the case of New South Wales. Paper presented at 1999 International Symposium on Society and Resource Management, Brisbane, 8 July.

Danzi, E. (1999) Irrigation water reforms, ABARE Current Issues, April.

Dudley, N. J. (1988) A single decision-maker approach to irrigation reservoir and farm management decision making, Water Resources Research, 24, pp. 633-640.

Dudley, N. J. \& Scott, B. W. (1993) Integrating irrigation water demand, supply, and delivery management in a stochastic environment, Water Resources Research, 29, pp. 3093-3101.

Economist (2000) The salt that won't run to the sea, 5 February, p. 38.

Howitt, R. E. \& M'Marete, M. (1989) The value of groundwater in adapting to drought: lessons from 1976-77, Coping with Water Scarcity: The Role of Ground Water. Proceedings of the Seventeenth Biennial Conference on Ground Water. Report 72, California Department of Water Resources.

Howitt, R. E., Watson, W. D. \& Nuckton, C. F. (1979) Efficiency and equity in management of agricultural water supplies. University of California, Giannini Foundation of Agricultural Economics, Information Series 79-1.

Jaffee, D. M. \& Russell, T. (1997) Catastrophe insurance, capital markets, and uninsurable risks, Journal of Risk and Insurance, 64, pp. 205-230.

Mahul, O. (2001) Optimal insurance against climatic experience, American Journal of Agricultural Economics, 83 , pp. 593-604.

Martin, S. W., Barnett, B. J. \& Coble, K. H. (2001) Developing and pricing precipitation insurance, Journal of Agricultural and Resource Economics, 26, pp. 261-274.

Miranda, M. J. (1991) Area-yield crop insurance reconsidered, American Journal of Agricultural Economics, 73, pp. $233-242$.

Musgrave, W. F. (1997) Australia, in: A. Dinar \& A. Subramanian (Eds) Water pricing experiences: an international perspective, pp. 17-23, World Bank Technical Paper 386, Washington, DC.

Patrick, G. F. (1988) Mallee wheat farmers' demand for crop and rainfall insurance, Australian Journal of Agricultural Economics, 32, pp. 37-49.

Podbury, T., Sheales, T. C., Hussain, I. \& Fisher, B. S. (1998) Use of El Nino climate forecasts in Australia, American Journal of Agricultural Economics, 80, pp. 1096-1101.

Quiggen, J. C. (1986) A note on the viability of rainfall insurance, Australian Journal of Agricultural Economics, 30 , pp. $63-69$.

Sanderson, F. (1943) A specific risk scheme for wheat crop insurance, Journal of Farm Economics, 25, pp. 759-776.

Skees, J. R. (2000) A role for capital markets in natural disasters: a piece of the food security puzzle, Food Policy, 25 , pp. 365-378.

Skees, J. R. \& Barnett, B. J. (1999) Conceptual and practical considerations for sharing catastrophic/systemic risks, Review of Agricultural Economics, 21, pp. 424-441.

Topp, V. \& McClintock, A. (1998) Efficiency and equity in water markets. Paper presented at the Australian National Committee on Irrigation and Drainage (ANCID) 1998 conference, Sale, Victoria, 2-5 August (Australian Bureau of Agriculture and Resource Economics (ABARE) Conference Paper 98.19).

Turvey, C. G. (2001) Weather derivatives for specific event risks in agriculture, Review of Agricultural Economics, 23, pp. 333-351. 